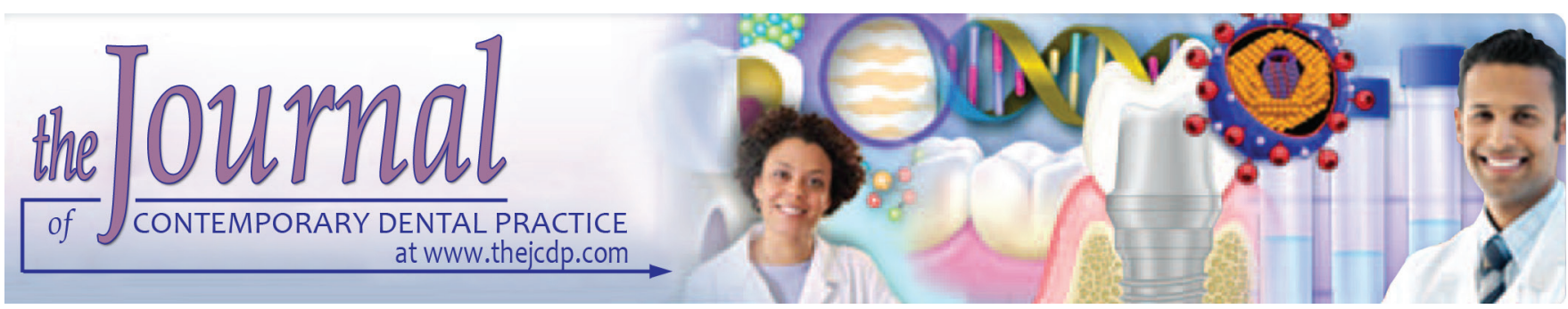

\title{
Effect of Sandblasting Angle and Distance on Biaxial Flexural Strength of Zirconia-based Ceramics
}

\author{
${ }^{1}$ Somayeh Zeighami, ${ }^{2}$ Ali Gheidari, ${ }^{3}$ Hoseinali Mahgoli, ${ }^{4}$ Ahmad Rohanian, ${ }^{5}$ Safoura Ghodsi
}

\begin{abstract}
Aim: Surface treatment is necessarily required for bonding of zirconia to the veneering porcelain and luting cements. Sandblasting is the most common and probably the most efficient surface treatment method. Sandblasting roughens the surface and may affect the flexural strength of zirconia. Different sandblasting protocols may yield variable results. This study sought to assess the effect of sandblasting angle and distance on the biaxial flexural strength of zirconia-based ceramics.
\end{abstract}

Materials and methods: This in vitro experimental study was conducted on 50 zirconia discs measuring $1.2 \pm 0.2 \mathrm{~mm}$ in thickness and $15 \pm 0.2 \mathrm{~mm}$ in diameter, which were randomly divided into five groups $(n=10)$ of one control and four experimental groups subjected to sandblasting with $110 \mu \mathrm{m}$ aluminum oxide particles under 2 bar pressure for 10 seconds at 15 and $25 \mathrm{~mm}$ distances and 45 and $90^{\circ}$ angles (between the nozzle head and zirconia surface). Surface roughness was measured by a roughness tester and samples were subjected to thermocycling followed by biaxial flexural strength testing according to ISO6872. The data were analyzed using one-way analysis of variance $(p<0.05)$.

Results: No statistically significant difference was noted in the mean biaxial flexural strength of the five groups $(p=0.40)$. Different sandblasting protocols yielded significantly different surface roughness values $(p<0.001)$. The highest and the lowest mean surface roughness belonged to $15 \mathrm{~mm} / 90^{\circ}(0.51 \mu \mathrm{m})$ and control $(0.001 \mu \mathrm{m})$ groups respectively.

Conclusion: Change in sandblasting angle and distance had no significant effect on the biaxial flexural strength of zirconiabased ceramic, but surface roughness was significantly different in the study groups.

\footnotetext{
1,3-5Dental Research Center, Dentistry Research Institute and Department of Prosthodontics, School of Dentistry Tehran University of Medical Sciences, Tehran, Islamic Republic of Iran

${ }^{2}$ Private Dental Clinic, Tehran, Islamic Republic of Iran

Corresponding Author: Safoura Ghodsi, Dental Research Center Dentistry Research Institute and Department of Prosthodontics School of Dentistry, Tehran University of Medical Sciences Tehran, Islamic Republic of Iran, Phone: +00989128450833, e-mail: safura_gh82@yahoo.com
}

Clinical significances: Regardless of sandblasting angle, increasing distance to $25 \mathrm{~mm}$ significantly decreases surface roughness that may negatively affect zirconia bond strength.

Keywords: Fracture, Laboratory research, Sandblast, Strength, Zirconia.

How to cite this article: Zeighami S, Gheidari A, Mahgoli $H$, Rohanian A, Ghodsi S. Effect of Sandblasting Angle and Distance on Biaxial Flexural Strength of Zirconia-based Ceramics. J Contemp Dent Pract 2017;18(6):443-447.

Source of support: This study has been supported by Dental Research Center, Dentistry Research Institute, Tehran University of Medical Sciences and Health Services, Tehran, Iran, Grant\# 29281-69-02-94.

\section{Conflict of interest: None}

\section{INTRODUCTION}

Metal-ceramic restorations are still commonly used for reconstruction of tooth crowns, ${ }^{1}$ but patient demands for more esthetic and durable restorations led to the fabrication of all-ceramic restorations. ${ }^{2}$ Advances were made in the fabrication of these restorations following the introduction of novel materials and techniques. ${ }^{3}$

Zirconia ceramics have gained the spotlight but selection of optimal surface treatment methods and luting cements to enhance the bond strength of zirconia or highly crystalline ceramics in general remains a challenge in dentistry. ${ }^{4}$ These ceramics have a small crystalline phase compared with the older types (silica-based ceramics); as a result, the commonly used methods to enhance the bond strength, such as hydrofluoric acid etching are not effective for roughening of surface, increasing the wettability and increasing the required surface for mechanical interlocking and use of silane before the application of resin cement due to the absence of silica are not much effective. ${ }^{5,6}$ Moreover, since zirconia has a neutral surface, ${ }^{7}$ it has a low potential for forming a chemical bond, and this compromises the union of zirconia substrate with cement. ${ }^{8}$ In other words, 
it appears that both micromechanical interlocking and chemical bond between the zirconia core and resin cement are hard to achieve. Resultantly, the common methods of bonding cannot provide the adequate bond strength of zirconia substrate to tooth structure or restorative materials and is a challenging issue. ${ }^{9}$ A previous study revealed that the bond of $7 \%$ of single crowns placed in the posterior areas was lost by the end of a 3-year observation period. ${ }^{10}$

On the contrary, high-strength ceramics are more opaque than the older types. Thus, to achieve optimal esthetics and favorable morphology, high-strength ceramics must be veneered with feldspathic porcelain. ${ }^{11,12}$ However, the mechanical properties and behavior of zirconia core and the veneering porcelain are different. ${ }^{4}$ Chipping and delamination of the veneering feldspathic porcelain are among the most common complications of these restorations, which lead to exposure of the underlying zirconia core. ${ }^{13,14}$ Such a high rate of fracture may be related to the loss of bond between the veneering porcelain and the underlying zirconia structure. ${ }^{15}$

Zirconia crowns are often subjected to surface treatment to enhance their wettability and bond strength of ceramic core to cement and also the bond of the external surface of core to the veneering porcelain. ${ }^{16,17}$ Zirconia surface treatment increases the surface roughness to obtain mechanical interlocking and chemically activates the surface to obtain a chemically strong bond. ${ }^{18}$ Sandblasting is among the most common and most efficient surface treatment methods, ${ }^{19}$ which enhance the bond of zirconia to the veneering ceramic and luting cement via mechanical interlocking. ${ }^{3}$

However, it should be noted that during the process of sandblasting, microcracks might form in the zirconia surface due to the impact of particles. These cracks may compromise the stability and durability of ceramics in the long term ${ }^{20}$ and degrade its strength. ${ }^{21-23}$ Impact of particles at high speed creates a rough surface, damages some superficial areas, and creates a residual compressive stress due to tetragonal to monoclinic phase transition. ${ }^{2,20,24}$ The sandblasting protocol determines the severity of damage, and variability in the results is due to differences in the type and size of particles, pressure, nozzle size, impact angle, and other parameters, such as microstructure of the substrate. ${ }^{19}$

Some researchers including Sato et $\mathrm{al}^{2} \mathrm{Ban}^{25}$ Souza et $\mathrm{al}^{26}$ Kosmac et $\mathrm{al}^{20,27,28}$ showed that biaxial flexural strength of zirconia after sandblasting was higher than that of the control group. In contrast, some others including Wang et $\mathrm{al}^{29}$ reported a reduction in biaxial flexural strength of zirconia after sandblasting. El-Naga et $\mathrm{al}^{30}$ demonstrated that sandblasting did not cause any significant change in the strength of zirconia.
Since the results are controversial and there is no definitive protocol for sandblasting, this study aimed to assess the effect of sandblasting angle and distance on the biaxial flexural strength of zirconia-based ceramic.

\section{MATERIALS AND METHODS}

\section{Fabrication of Samples}

Fifty yttria-stabilized tetragonal zirconia polycrystal (Y-TZP) zirconia discs (Cercon, Dentsply, Germany) were fabricated by milling of semi-sintered zirconia blocks using Cercon Expert milling machine (Cercon, Dentsply, Germany). The samples were then sintered in Cercon Heat Plus furnace (Cercon, Dentsply, Germany) at $1,350^{\circ} \mathrm{C}$. Discs were then polished with 600,800 , and 1,000 grit silicon carbide papers under running water to match their thickness and surface roughness. The samples (measuring 1.2 $\pm 0.2 \mathrm{~mm}$ in thickness and $15 \pm 0.2 \mathrm{~mm}$ in diameter) were then randomly divided into five groups $(\mathrm{n}=10)$. A no-sandblasting control group was also included in the study.

\section{Sandblasting}

The four experimental groups were subjected to sandblasting (Mestra galaxy sandblaster, Argibond, England) by $110 \mu \mathrm{m}$ aluminum oxide particles (Aluminium Oxide, Edelkorund, Germany) under 2 bar pressure for 10 seconds. The experimental groups were as follows:

- Sandblasting at $45^{\circ}$ impact angle and $15 \mathrm{~mm}$ distance - Sandblasting at $45^{\circ}$ impact angle and $25 \mathrm{~mm}$ distance

- Sandblasting at $90^{\circ}$ impact angle and $15 \mathrm{~mm}$ distance

- Sandblasting at $90^{\circ}$ impact angle and $25 \mathrm{~mm}$ distance.

\section{Assessment of Surface Roughness by Profilometry}

Before the assessment of surface roughness ( $\mathrm{Ra}$ ), the samples were placed in an ultrasonic bath (Eurosonic $4 \mathrm{D}$, Euronda, Italy) containing $20^{\circ} \mathrm{C}$ distilled water for 5 minutes to eliminate impurities. The samples were then air-dried with air spray, and their surface roughness was measured by a portable surface roughness tester (Qualitest TR200, USA).

\section{Biaxial Flexural Strength Testing}

To simulate the oral environment in terms of moisture, thermal changes, and aging of restorations, the samples were subjected to thermocycling (TC-300, Vafaei Industrial, Iran) before flexural strength testing. For this purpose, the samples were subjected to 5,000 thermal cycles (corresponding to 6 months of clinical service) between 5 and $55^{\circ} \mathrm{C}$ with a dwell time of 15 seconds and transfer time of 10 seconds. Biaxial flexural strength test was then 
performed using a universal testing machine (Zwick Roell, Ulm, Germany) according to ISO6872 standard.

\section{Statistical Analysis}

One-way analysis of variance was used to compare the mean surface roughness and biaxial flexural strength values of the five groups. Pairwise comparison of the groups was carried out using Tukey's test or GamesHowell test. Level of significance was set at $p<0.05$.

\section{RESULTS}

\section{Biaxial Flexural Strength}

The mean and standard deviation (SD) of biaxial flexural strength values in the five groups are presented in Table 1. Statistically, no significant difference was found among the five groups in the mean biaxial flexural strength $(\mathrm{p}=0.40)$.

\section{Surface Roughness}

Data regarding the mean and SD of surface roughness values in the five groups and their comparisons are presented in Tables 1 and 2. Based on the results, different sandblasting protocols caused significant differences in surface roughness of the five groups $(p<0.001)$.

\section{DISCUSSION}

This study aimed to assess the effect of different sandblasting protocols on the biaxial flexural strength of zirconia.

Table 1: Mean and SD of biaxial flexural strength and surface roughness in the five groups $(n=10)$

\begin{tabular}{lll}
\hline & $\begin{array}{l}\text { Mean biaxial flexural } \\
\text { strength }(\mathrm{MPa})\end{array}$ & $\mathrm{S} D$ \\
\hline $15 \mathrm{~mm} / 45^{\circ}$ & $1070.83 \pm 203.76$ & $0.33 \pm 0.24$ \\
$25 \mathrm{~mm} / 45^{\circ}$ & $1015.57 \pm 104.09$ & $0.002 \pm 0.0007$ \\
$15 \mathrm{~mm} / 90^{\circ}$ & $976.60 \pm 152.24$ & $0.51 \pm 0.13$ \\
$25 \mathrm{~mm} / 90^{\circ}$ & $983.63 \pm 129.38$ & $0.13 \pm 0.19$ \\
Control & $930.33 \pm 108.92$ & $0.001 \pm 0.0005$ \\
\hline
\end{tabular}

SD: Standard Deviation

Table 2: Pairwise comparisons of mean and standard error of surface roughness values in the five groups

\begin{tabular}{lllll}
\hline Group & Group & $\begin{array}{l}\text { Mean } \\
\text { difference }\end{array}$ & $\begin{array}{l}\text { Standard } \\
\text { error }\end{array}$ & $p$-value \\
\hline $15 \mathrm{~mm} / 45^{\circ}$ & $25 \mathrm{~mm} / 45^{\circ}$ & 0.32 & 0.084 & $0.03^{*}$ \\
& $15 \mathrm{~mm} / 90^{\circ}$ & -0.18 & 0.09 & 0.37 \\
& $25 \mathrm{~mm} / 90^{\circ}$ & 0.19 & 0.10 & 0.40 \\
& Control & 0.32 & 0.08 & $0.03^{*}$ \\
$25 \mathrm{~mm} / 45^{\circ}$ & $15 \mathrm{~mm} / 90^{\circ}$ & -0.51 & 0.05 & $0.001<^{*}$ \\
& $25 \mathrm{~mm} / 90^{\circ}$ & -0.13 & 0.06 & 0.38 \\
$15 \mathrm{~mm} / 90^{\circ}$ & Control & 0.00 & 0.00 & 0.74 \\
& $25 \mathrm{~mm} / 90^{\circ}$ & 0.38 & 0.08 & $0.005^{*}$ \\
$25 \mathrm{~mm} / 90^{\circ}$ & Control & 0.51 & 0.05 & $0.001<^{*}$ \\
\hline
\end{tabular}

*Statistically significant $(p<0.05)$
Simultaneous effects of angle and distance between the nozzle and surface on bond strength of zirconia have been less commonly evaluated. The reason may be that accurate adjustment of angle and distance simultaneously is more difficult compared with other factors and is less feasible in conventional sandblasters. In studies, which did not intend to assess the effect of impact angle, sandblasting was done vertical to the surface. Chintapalli et $\mathrm{al}^{19}$ evaluated the effect of sandblasting with 30 and $90^{\circ}$ angles and Moon et $\mathrm{al}^{31}$ compared 45 and $90^{\circ}$ angles. No previous study was found on the effect of changing the distance of sandblasting on the flexural strength. However, the distance from the sandblaster to the surface in different studies has been variable ranging from 10 to $30 \mathrm{~mm}$. These studies have suggested some protocols to achieve the best results in terms of surface roughness and highest bond strength. In 2013, Chintapalli et $\mathrm{al}^{32}$ recommended mild sandblasting with $110 \mu \mathrm{m}$ particles under 2 bar pressure due to insignificant damage to the surface. In contrast, intense sandblasting with $250 \mu \mathrm{m}$ particles under 4 bar pressure can cause significant damage not tolerable by the layer with concentrated compressive stress. ${ }^{32}$ Moon et $\mathrm{al}^{31}$ recommended sandblasting with $50 \mu \mathrm{m}$ alumina particles under 4 bar pressure for 20 seconds at $45^{\circ}$ or $90^{\circ}$ angle to achieve maximum bond strength to resin cement.

Aurélio et $\mathrm{al}^{33}$ in their review study in 2016, concluded that in general, sandblasting improved the flexural strength of Y-TZP ceramics irrespective of the size of particles, sandblasting pressure and its duration. Slikkerveer et $\mathrm{al}^{34}$ discussed that since particles have less energy in lower pressures, damage would be limited to plastic deformation around the impact site. In higher velocities, higher kinetic energy of particles may create tensile stresses around the impact site and cause cracks.

Chintapalli et al ${ }^{19}$ observed that the strength of zirconia further increased in low pressures because the defects created by sandblasting were less or slightly higher than the initial natural critical defects that are primarily present in the zirconia surface. In both conditions, the positive effect of the created compressive stress is high enough to overcome the created damage. Chintapalli et $\mathrm{al}^{19}$ believed that the interaction effect of the residual compressive stress and the created damage would determine the increase or decrease in the strength of zirconia, and their interaction effect at a certain pressure and particle size depends on the impact angle.

In this study, changing the distance and impact angle of sandblasting with $110 \mu \mathrm{m}$ alumina particles under 2 bar pressure for 10 seconds did not cause a significant change in the biaxial flexural strength of Y-TZP ceramic. However, the mean flexural strength of the four sandblasted groups showed a slight increase compared with the control group. These findings confirmed those of 
previous studies and revealed that sandblasting increased the flexural strength of zirconia. Furthermore, our findings showed that changing the distance and impact angle of sandblasting did not cause a significant change in the flexural strength of zirconia. Increase in flexural bond strength after sandblasting is attributed to the tetragonal to monoclinic phase transformation, which creates residual compressive stress. In fact, stresses created and concentrated at the tip of the cracks (present on the surface before sandblasting or later created by sandblasting) prevent crack propagation and consequently increase the strength of substrate. . $20,25^{2}$

The results of the current study revealed that sandblasting increased the surface roughness. This increase in surface roughness of sandblasted samples at $15 \mathrm{~mm}$ distance was significantly higher than that of the control group. The samples sandblasted at $25 \mathrm{~mm}$ distance showed a slight increase in surface roughness. In contrast to sandblasting at $15 \mathrm{~mm}$ distance, sandblasting at $25 \mathrm{~mm}$ distance could not provide adequate surface roughness for bonding. The results of the current study showed that irrespective of the angle of impact, reduction in distance significantly increased the surface roughness. This result may be due to higher energy of particles impacting the zirconia surface at a closer distance, which may result in fracture or delamination of the surface. Most previous studies concluded that different sandblasting protocols increased the surface roughness ${ }^{35,36}$ and enhanced the bond to zirconia. ${ }^{37,38}$ Moon et al ${ }^{31}$ revealed that increase in surface roughness was proportionate to the size of particles, duration of sandblasting, and angle of impact.

Future studies are required to simultaneously assess the effect of parameters involved in changes in mechanical structure and surface topography caused by sandblasting. Moreover, clinical studies are necessary to test the efficacy of methods and protocols suggested in experimental studies.

\section{CONCLUSION}

Within the limitations of this in vitro study (which could not perfectly simulate the oral clinical setting), the following results were obtained:

- Change in distance and impact angle of sandblasting had no significant effect on biaxial flexural strength of zirconia-based ceramic.

- Changing the distance of sandblasting caused a significant change in surface roughness of zirconia-based ceramic.

- Sandblasting with $110 \mu \mathrm{m}$ alumina particles under 2 bar pressure for 10 seconds at $15 \mathrm{~mm}$ distance, irrespective of the angle of impact, slightly increased the biaxial flexural strength of zirconia and yielded the highest surface roughness $(\mathrm{Ra})$ value.

\section{CLINICAL SIGNIFICANCE}

Regardless of sandblasting angle, increasing distance to $25 \mathrm{~mm}$ significantly decreased surface roughness that may negatively affect zirconia bond strength.

\section{ACKNOWLEDGMENTS}

The authors express their appreciation to Dr Ahmad Reza Shamshiri for his statistical consultation and Mr. Esmaeel Hasanzadeh for his technical help in the laboratory work.

\section{REFERENCES}

1. Stevenson B, Ibbetson R. The effect of the substructure on the colour of samples/restorations veneered with ceramic: a literature review. J Dent 2010 May;38(5):361-368.

2. Sato H, Yamada K, Pezzotti G, Nawa M, Ban S. Mechanical properties of dental zirconia ceramics changed with sandblasting and heat treatment. Dent Mater J 2008 May;27(3):408-414.

3. Miyazaki T, Nakamura T, Matsumura H, Ban S, Kobayashi T. Current status of zirconia restoration. J Prosthodont Res 2013 Oct;57(4):236-261.

4. Ferrari M, Vichi A, Zarone F. Zirconia abutments and restorations: from laboratory to clinical investigations. Dent Mater 2015 Mar;31(3):e63-e76.

5. CavalcantiAN, Foxton RM, Watson TF, Oliveira MT, GianniniM, Marchi GM. Y-TZP ceramics: key concepts for clinical application. Oper Dent 2009 May-Jun;34(3):344-351.

6. Vagkopoulou T, Koutayas SO, Koidis P, Strub JR. Zirconia in dentistry: part 1. Discovering the nature of an upcoming bioceramic. Eur J Esthet Dent 2009 Summer;4(2):130-151.

7. Hao L, Lawrence J, Chian KS. Osteoblast cell adhesion on a laser modified zirconia based bioceramic. J Mater Sci Mater Med 2005 Aug;16(8):719-726.

8. Lohbauer U, Zipperle M, Rischka K, Petschelt A, Müller FA. Hydroxylation of dental zirconia surfaces: characterization and bonding potential. J Biomed Mater Res B Appl Biomater 2008 Nov;87(2):461-467.

9. Blatz MB, Chiche G, Holst S, Sadan A. Influence of surface treatment and simulated aging on bond strengths of luting agents to zirconia. Quintessence Int 2007 Oct;38(9):745-753.

10. Ortorp A, Kihl ML, Carlsson GE. A 3-year retrospective and clinical follow-up study of zirconia single crowns performed in a private practice. J Dent 2009 Sep;37(9):731-736.

11. Bidra AS, Rungruanganunt P. Clinical outcomes of implant abutments in the anterior region: a systematic review. J Esthet Restor Dent 2013 Jun;25(3):159-176.

12. Sailer I, Zembic A, Jung RE, Siegenthaler D, Holderegger C, Hämmerle $\mathrm{CH}$. Randomized controlled clinical trial of customized zirconia and titanium implant abutments for canine and posterior single-tooth implant reconstructions: preliminary results at 1 year of function. Clin Oral Implants Res 2009 Mar;20(3):219-225.

13. Zeighami S, Mahgoli H, Farid F, Azari A. The effect of multiple firings on microtensile bond strength of core-veneer zirconia-based all-ceramic restorations. J Prosthodont 2013 Jan;22(1):49-53.

14. Sailer I, Pjetursson BE, Zwahlen M, Hämmerle CH. A systematic review of the survival and complication rates of all-ceramic and metal-ceramic reconstructions after an 
observation period of at least 3 years. Part II: fixed dental prostheses. Clin Oral Implants Res 2007 Jun;18(Suppl3):86-96.

15. Raigrodski AJ. Contemporary materials and technologies for all-ceramic fixed partial dentures: a review of the literature. J Prosthet Dent 2004 Dec;92(6):557-562.

16. Gahlert M, Gudehus T, Eichhorn S, Steinhauser E, Kniha H, Erhardt W. Biomechanical and histomorphometric comparison between zirconia implants with varying surface textures and a titanium implant in the maxilla of miniature pigs. Clin Oral Implants Res 2007 Oct;18(5):662-668.

17. Fischer J, Grohmann P, Stawarczyk B. Effect of zirconia surface treatments on the shear strength of zirconia/veneering ceramic composites. Dent Mater J 2008 May;27(3):448-454.

18. Piascik JR, Swift EJ, Thompson JY, Grego S, Stoner BR. Surface modification for enhanced silanation of zirconia ceramics. Dent Mater 2009 Sep;25(9):1116-1121.

19. Chintapalli RK,Mestra RodriguezA, Garcia MarroF,AngladaM. Effect of sandblasting and residual stress on strength of zirconia for restorative dentistry applications. J Mech Behav Biomed Mater 2014 Jan;29:126-137.

20. Kosmač T, Oblak C, Jevnikar P, Funduk N, Marion L. The effect of surface grinding and sandblasting on flexural strength and reliability of Y-TZP zirconia ceramic. Dent Mater 1999 Nov;15(6):426-433.

21. Zhang Y, Lawn BR, Malament KA, Van Thompson P, Rekow ED. Damage accumulation and fatigue life of particleabraded ceramics. Int J Prosthodont 2006Sep-Oct;19(5):442-448.

22. Thompson JY, Stoner BR, Piascik JR, Smith R. Adhesion/ cementation to zirconia and other non-silicate ceramics: Where are we now? Dent Mater 2011 Jan;27(1):71-82.

23. Karakoca S, Yilmaz H. Influence of surface treatments on surface roughness, phase transformation, and biaxial flexural strength of Y-TZP ceramics. J Biomed Mater Res B Appl Biomater 2009 Nov;91(2):930-937.

24. Zhang Y, Lawn BR, Rekow ED, Thompson VP. Effect of sandblasting on the long-term performance of dental ceramics. J Biomed Mater Res B Appl Biomater 2004 Nov;71(2):381-386.

25. Ban S. Reliability and properties of core materials for all-ceramic dental restorations. Jpn Dent Sci Rev 2008 Jul;44(1):3-21.

26. Souza RO, Valandro LF, Melo RM, Machado JP, Bottino MA, Ozcan M. Air-particle abrasion on zirconia ceramic using different protocols: effects on biaxial flexural strength after cyclic loading, phase transformation and surface topography. J Mech Behav Biomed Mater 2013 Oct;26:155-163.

27. Kosmač T, Oblak C, Jevnikar P, Funduk N, Marion L. Strength and reliability of surface treated Y-TZP dental ceramics. J Biomed Mater Res 2000 Feb;53(4):304-313.

28. Kosmač T, Dakskobler A, Oblak Č, Jevnikar P. The strength and hydrothermal stability of Y-TZP ceramics for dental applications. Int J Appl Ceram Technol 2007 Mar;4(2):164-174.

29. Wang H, Aboushelib MN, Feilzer AJ. Strength influencing variables on CAD/CAM zirconia frameworks. Dent Mater 2008 May;24(5):633-638.

30. El-Naga AA, El-fallal AA, Ibraheim SA, Alaraby HA. Fracture strength of two zirconia all-ceramic crown systems: influence of intaglio surface conditioning. Mansoura J Dent 2014;1(3):67-71.

31. Moon JE, Kim SH, Lee JB, Han JS, Yeo IS, Ha SR. Effects of airborne-particle abrasion protocol choice on the surface characteristics of monolithic zirconia materials and the shear bond strength of resin cement. Ceram Int 2016 Jan;42(1):1552-1562.

32. Chintapalli RK, Marro FG, Jimenez-Pique E, Anglada M. Phase transformation and subsurface damage in 3Y-TZP after sandblasting. Dent Mater 2013 May;29(5):566-572.

33. Aurélio IL, Marchionatti AM, Montagner AF, May LG, Soares FZ. Does air particle abrasion affect the flexural strength and phase transformation of Y-TZP? A systematic review and meta-analysis. Dent Mater 2016 Jun;32(6):827-845.

34. Slikkerveer PJ, Bouten PC, de Haas FC. High quality mechanical etching of brittle materials by powder blasting. Sens Actuators A Phys 2000 Aug;85(1-3):296-303.

35. Arami S, Tabatabae MH, Namdar SF, Chiniforush N. Effects of different lasers and particle abrasion on surface characteristics of zirconia ceramics. J Dent (Tehran) 2014 Mar;11(2):233-241.

36. Ozcan M, Melo RM, Souza RO, Machado JP, Felipe Valandro L, Botttino MA. Effect of air-particle abrasion protocols on the biaxial flexural strength, surface characteristics and phase transformation of zirconia after cyclic loading. J Mech Behav Biomed Mater 2013 Apr;20:19-28.

37. Wolfart M, Lehmann F, Wolfart S, Kern M. Durability of the resin bond strength to zirconia ceramic after using different surface conditioning methods. Dent Mater 2007 Feb;23(1):45-50.

38. Kern M, Barloi A, Yang B. Surface conditioning influences zirconia ceramic bonding. J Dent Res 2009 Sep;88(9):817-822. 